\begin{tabular}{|cc|}
\hline HARDWOOD & ALDER \\
LIGNIN & PYROLYSIS \\
METHOXYPHENOLS & GC - MS \\
SEPARATION & IDENTIFICATION \\
PEROXIDATION & PROTECTION \\
\hline
\end{tabular}

Open access revised manuscript version of

Food Chemistry 74 (2001) 85-89

Link to publisher: doi:10.1016/S0308-8146(01)00102-9

\title{
Phenolic antioxidants in alder smoke during industrial meat curing
}

\author{
Jennica Kjällstrand and Göran Petersson
}

A related basic study of the most prominent dimethoxyphenols:

Phenolic antioxidants in wood smoke 


\title{
Phenolic antioxidants in alder smoke
}

\author{
during industrial meat curing
}

\author{
Jennica Kjällstrand, Göran Petersson* \\ Department of Chemical Environmental Science, Chalmers University of Technology, \\ SE-41296 Göteborg, Sweden
}

\begin{abstract}
Alder wood smoke in a large sausage-curing chamber was analysed with regard to its content of methoxyphenol antioxidants. The use of Tenax adsorbent cartridges permitted simultaneous quantitative sampling of phenols condensed on smoke particles as well as gaseous compounds. The analytical determinations were performed by thermal desorption combined with gas chromatography and mass spectrometry. In addition to methoxyphenols, several other key components were assessed, including 1,6-anhydroglucose, 2-furaldehyde, furans and hydrocarbons. Benzene was the most prominent hydrocarbon. The concentrations of polycyclic aromatic compounds were low, due to a low smoke generation temperature.

Predominant smoke components were the 2,6-dimethoxyphenols, which are characteristic thermal degradation products from hardwood. The 2,6-dimethoxyphenols are stronger antioxidants than the 2-methoxyphenols present in lower amounts. The particularly active antioxidants with a 4-alkenyl side-chain constituted 20-30\% of total methoxyphenols, which is
\end{abstract}


much more than normally reported for liquid smoke. The phenolic antioxidants may be important not only for the preservation of foods, but also for health as dietary components.

Keywords: Hardwood, Smouldering combustion, Methoxyphenols, Furans, Benzene, Phenoxy radicals, Lipid peroxidation

* Corresponding author Fax: +46 31 7722999: E-mail address: goranp@kmv.chalmers.se

\section{Introduction}

Smoke curing of food, including ham, sausages and fish, is an old technique for flavouring and preservation, which is presently extensively used in industrial modified versions. The chemical aspects of meat smoking have been reviewed (Toth \& Potthast, 1984), and the chemical composition of smoke condensates and liquid smoke has been assessed in many studies, including some recent investigations (Guillén \& Ibargoitia, 1998, 1999). Methoxyphenols are major components of great importance for the smoke flavour and for the preserving antioxidant effect of the smoke. High antioxidant activities on lipid peroxidation have recently been demonstrated in model assays for several specific methoxyphenols related to those occurring in wood smoke (Barclay, Xi \& Norris, 1997; Ogata, Hoshi, Shimotohno, Urano \& Endo, 1997).

The chemical composition of freshly generated smoke in curing chambers is more difficult to assess than that of liquid smoke. Phenols and other smoke components occur either gaseous or condensed on particles, or both (Hawthorne, Krieger, Miller \& Mathiason, 1989). The aim of this study was to apply an analytical technique permitting determination of all prominent methoxyphenols and a range of other compounds. Similar assessments have previously been 
made for smoke from forest biomass burning (Kjällstrand, Ramnäs \& Petersson, 2000) and for chimney emissions of wood smoke (Kjällstrand \& Petersson, 2001a). An additional aim was to elucidate relative proportions and effects of curing smoke antioxidants. The antioxidant properties of specific methoxyphenols in birchwood smoke were recently characterised (Kjällstrand \& Petersson, 2001b).

\section{Materials and methods}

\subsection{Smoke generation}

Curing smoke was generated continuously by smouldering combustion in a $5-10 \mathrm{~cm}$ thick bed of commercial pea-size wood particles, including bark, from alder (Alnus glutinosa). An airflow through the enclosed smoke generator transported smoke into the curing room $\left(120 \mathrm{~m}^{3}\right.$, $24^{\circ} \mathrm{C}$ ) filled with sausages hanging on mobile equipment. In our laboratory, smoke was generated by choked burning of match-size wood sticks, as previously described for other biomass materials (Kjällstrand et al., 2000).

\subsection{Analytical methods}

Samples of 4-5 $\mathrm{ml}$ were taken during approximately $1 \mathrm{~min}$ with a conventional air pump. The adsorbent cartridges were injector glass liners $(0.8 \mathrm{~mm}$ i.d.) filled with the porous polymer Tenax TA (60-80 mesh). In the laboratory, thermal desorption was performed at $220^{\circ} \mathrm{C}$ in the injector of the gas chromatograph (Varian 3800) with the helium carrier gas. The separations 
were made on a fused silica open tubular column (30 $\mathrm{m} \times 0.25 \mathrm{~mm}$ i.d.) with a cyanopropylphenylsilicone ( $\operatorname{tx} 1701,0.25 \mu \mathrm{m}$ layer) as the stationary phase. The oven temperature was increased $10^{\circ} \mathrm{C} \min ^{-1}$ from $-50^{\circ} \mathrm{C}$ to $50^{\circ} \mathrm{C}$ and then $5^{\circ} \mathrm{C} \mathrm{min}^{-1}$ from $50^{\circ} \mathrm{C}$ to $250^{\circ} \mathrm{C}$. The column outlet was connected to a Varian Saturn 2000 ion trap mass spectrometer. Electron impact mass spectra $(70 \mathrm{eV}, \mathrm{m} / \mathrm{z} 35-400)$ were recorded. Concentrations were calculated using the response of methoxyphenols (Kjällstrand et al., 2000) for all compounds. The reported methoxyphenols were previously identified in smoke from forest biomass (Kjällstrand et al., 2000), and their identities were confirmed by retention times and mass spectra. Remaining assessed compounds were unequivocally identified by their mass spectra and are known prominent wood smoke components from previous studies of hydrocarbons (Barrefors \& Petersson, 1995), furans (Barrefors, Björkqvist, Ramnäs \& Petersson, 1996) and chimney emissions (Kjällstrand \& Petersson, 2001a)

\section{Results and discussion}

Concentrations of total methoxyphenols and key species of other compound classes are given in Table 1 for three smoking chamber samples, and one laboratory sample of smoke from choked burning of alder wood. Percent compositions of the methoxyphenols are given in Table 2 for the same samples. The total ion chromatogram in Fig. 1, for the second smoke sample, illustrates the separation of prominent assessed smoke components. 


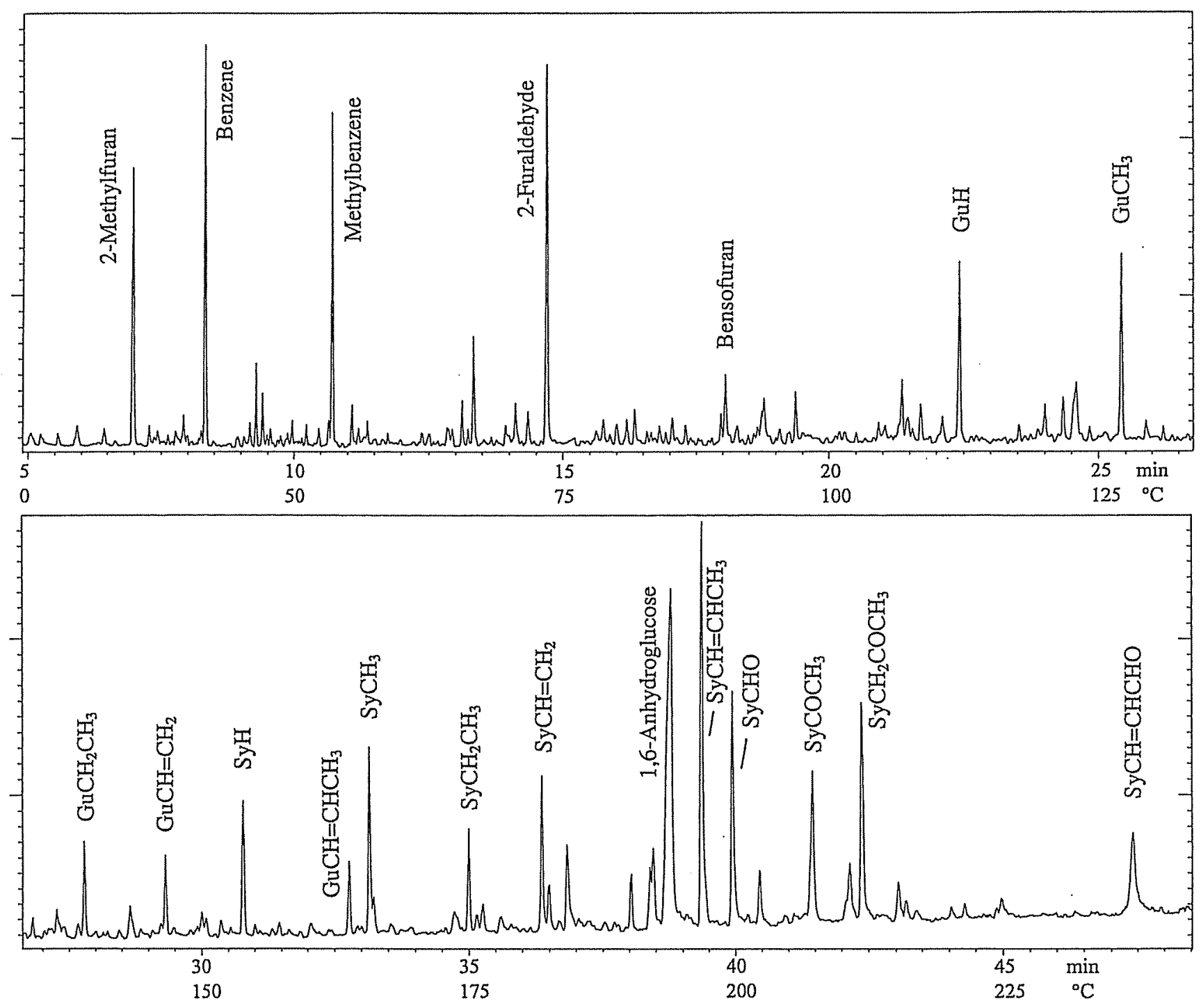

Fig. 1. Total ion chromatogram illustrating the separation of components of alder smoke from a curing chamber (second sample in Tables 1 and 2; the same attenuation for the two halves of the chromatogram). 


\subsection{Smoke composition}

As seen from Table 1, the methoxyphenols are major smoke components. The 2methoxyphenols constitute 20-30\% and the 2,6-dimethoxyphenols $70-80 \%$ of total methoxyphenols. A high proportion of 2,6-dimethoxyphenols is characteristic of hardwood smoke, whereas smoke from softwood biomass contains 2-methoxyphenols only (Kjällstrand et al., 2000). The smoke methoxyphenols reflect the structure of the corresponding units in the plant lignin. Liquid smoke from hardwood often contains lowered proportions of 2,6dimethoxyphenols (Tóth \& Potthast, 1984; Guillén \& Ibargoitia, 1999). This is probably explained by losses with removed particles during production.

The concentration of phenol as well as of methylphenols, dimethylphenols and ethylphenols was very low. With increasing combustion temperature, the proportion of these phenols increases relative to the methoxyphenols (Alén, Kuoppala \& Oesch, 1996). The much higher proportions of phenol and alkylphenols reported for many liquid smoke preparations (Tóth \& Potthast, 1984) are therefore explained by higher smoke generation temperatures than in the studied alder smoke generator.

The major carbohydrate-derived smoke component was 1,6-anhydroglucose, as expected from its well-known formation from cellulose and its presence in smoke from a wide variety of plant materials (Simoneit et al., 1999). The very polar structure makes 1,6-anhydroglucose difficult to analyse by gas chromatography, and it is often not reported. The 2-furaldehydes are less polar and more volatile carbohydrate degradation products. Furfural, 2-furaldehyde, is the major compound, which may be even more prominent in liquid smoke (Guillén \& Ibargoitia, 1999). 
Table 1. Concentrations $\left(\mathrm{mg} \mathrm{m}^{-3}\right.$ ) of selected components of alder smoke during industrial curing $\left(24^{\circ} \mathrm{C}\right)$ of sausages.

\begin{tabular}{lcccc}
\hline & \multicolumn{3}{c}{$\begin{array}{c}\text { Smoke curing chamber } \\
\text { Consecutive samples }\end{array}$} & $\begin{array}{c}\text { Choked lab. } \\
\text { burning } \\
4.2 \mathrm{ml}\end{array}$ \\
\hline Phenols & $4.1 \mathrm{ml}$ & $4.3 \mathrm{ml}$ & $4.5 \mathrm{ml}$ & 143 \\
2,6-Dimethoxyphenols & 16.8 & 16.1 & 12.1 & 39 \\
2-Methoxyphenols & 5.3 & 5.3 & 4.6 & 1.7 \\
Phenol & 0.2 & 0.2 & 0.2 & - \\
Anhydrosugars & & & 4.8 & 12 \\
1,6-Anhydroglucose & 5.8 & 6.0 & & 0.9 \\
Furaldehydes & & & 2.1 & 1.3 \\
2-Furaldehyde & 2.0 & 2.5 & 0.2 & 0.5 \\
5-Methyl-2-furaldehyde & 0.3 & 0.3 & 1.5 & 0.7 \\
Furans & & & 0.3 & 6.8 \\
2-Methylfuran & 1.9 & 1.6 & 0.4 & 4.4 \\
2,5-Dimethylfuran & 0.3 & 0.3 & 1.9 & 1.3 \\
Bensofuran & 0.4 & 0.4 & 1.3 & 2.0 \\
Hydrocarbons & & & 0.2 & \\
Benzene & 2.2 & 2.2 & 0.2 & \\
Methylbenzene & 1.5 & 1.4 & 0.2 & \\
Styrene & 0.2 & 0.2 & & \\
Naphthalene & 0.2 & &
\end{tabular}


The most prominent volatile alkylfuran was 2 -metylfuran. Furan is probably formed in similar amounts but was partially lost by break-through on sampling. Characteristic proportions between furan and several alkylfurans were given in a previous study of smoke from smouldering combustion of hardwood (Barrefors, Björkqvist, Ramnäs \& Petersson, 1996). The proportions of the furans are lower in smoke from flaming combustion.

Benzene was the major aromatic hydrocarbon in the smoke, followed by methylbenzene (toluene), dimethylbenzene (xylene), ethylbenzene and ethenylbenzene (styrene), in accordance with previous studies of wood smoke (Barrefors \& Petersson, 1995). As seen from Table 1, the proportions of the volatile hydrocarbons relative to the methoxyphenols were lower for choked burning. Complementary samples also demonstrated lower proportions of the volatile furans and hydrocarbons in the smoke generator than in the smoking chamber. It is concluded that the gaseous compounds are absorbed less efficiently than the particle-associated compounds during smoke curing. Liquid smoke prepared by aqueous extraction is not expected to contain significant amounts of volatile furans and hydrocarbons.

The concentration of naphthalene was only $0.2 \mathrm{mg} \mathrm{m}^{-3}$ in the smoke curing chamber, and the concentration of phenanthrene was determined by selective ion monitoring to be as low as $0.01 \mathrm{mg} \mathrm{m}^{-3}$. This contrast sharply with the high concentrations of these three hydrocarbons in smoke from wood burning for heating purposes (Kjällstrand \& Petersson, 2001a), and is explained by the rapid increase of emissions of polycyclic hydrocarbons with the combustion temperature (Alén et al., 1996). Phenanthrene is indicative of the presence of polycyclic aromatic compounds with higher molecular weight. Genotoxic and carcinogenic compounds with these structures in smoked food products (Tóth \& Potthast, 1984) may constitute important health hazards, and concentrations lower than specified limits are required (García-Falcón, González- 
Amigo, Lage-Yusty, López de Alda-Villaizán \& Simal-Lozano, 1996). Cytotoxic effects of liquid smoke have recently been demonstrated (Putnam, Bombick, Avalos \& Doolittle, 1999).

Most of the assessed compounds are polar in nature, but are favourably separated on the polar stationary phase used. As illustrated in Fig. 1, the 2-methoxyphenols appear before the corresponding 2,6-dimethoxyphenols in the chromatogram, and the structural analogues within the two compound groups elute in the same sequence. Small sampling volumes permitted determination of the volatile compounds 2 -methylfuran and benzene without significant breakthrough losses. The Tenax sampling technique is favourable for compounds appearing both as vapours and condensed on particles. Such semi-volatile compounds are easily lost when condensates are analysed and when particulate sampling filters are used (Hawthorne et al., 1989).

\subsection{Methoxyphenol proportions}

The specific composition of the methoxyphenols is outlined in Table 2 as percentages of the 21 assessed compounds. The thirteen 2,6-dimethoxyphenols differ only in the structure of the group in para position relative to the phenolic hydroxyl group. All analogous 2-methoxyphenols are formed, but those present in very small amounts are not reported. The two groups of methoxyphenols are often viewed as 4-hydroxy-3,5-dimethoxyphenyl (syringyl, Sy) and 4hydroxy-3-methoxyphenyl (guaiacyl, Gu) compounds. The percentage composition is very uniform for the three smoking chamber samples, indicating a good reproducibility for the analytical approach.

The steady-state smouldering combustion in the smoke generator differs from the choked laboratory burning, which includes smoke from flaming combustion at higher temperature. The proportions of the carbonyl-containing methoxyphenols are higher in the curing smoke from 
Table 2. Composition (\%) of alder smoke methoxyphenols, arranged in order of estimated decreasing antioxidant activity (Sy = syringyl = 4-hydroxy-3,5-dimethoxyphenyl; $\mathrm{Gu}=$ guaiacyl = 4-hydroxy-3-methoxyphenyl).

\begin{tabular}{|c|c|c|c|c|}
\hline \multirow{2}{*}{$\begin{array}{l}\text { Phenols } \\
\text { SyCH=CHCH}(E)\end{array}$} & \multicolumn{3}{|c|}{$\begin{array}{l}\text { Smoke curing chamber } \\
\text { Consecutive samples }\end{array}$} & \multirow{2}{*}{$\begin{array}{c}\begin{array}{c}\text { Choked lab. } \\
\text { burning }\end{array} \\
16.8\end{array}$} \\
\hline & 14.3 & 15.9 & 15.5 & \\
\hline $\mathrm{SyCH}=\mathrm{CHCH}_{3}(\mathrm{Z})$ & 1.8 & 1.8 & 1.8 & 2.8 \\
\hline $\mathrm{SyCH}=\mathrm{CH}_{2}$ & 4.8 & 5.8 & 4.9 & 9.6 \\
\hline $\mathrm{SyCH}_{2} \mathrm{CH}=\mathrm{CH}_{2}$ & 1.5 & 1.8 & 1.8 & 3.9 \\
\hline $\mathrm{SyCH}_{2} \mathrm{CH}_{2} \mathrm{CH}_{3}$ & 1.5 & 1.8 & 1.8 & 1.7 \\
\hline $\mathrm{SyCH}_{2} \mathrm{CH}_{3}$ & 2.9 & 3.3 & 3.1 & 4.3 \\
\hline $\mathrm{SyCH}_{3}$ & 5.5 & 6.5 & 5.8 & 8.7 \\
\hline $\mathrm{SyCH}_{2} \mathrm{COCH}_{3}$ & 8.5 & 8.7 & 8.8 & 4.5 \\
\hline $\mathrm{GuCH}=\mathrm{CHCH}_{3}(E)$ & 2.2 & 2.5 & 2.7 & 4.2 \\
\hline $\mathrm{GuCH}=\mathrm{CH}_{2}$ & 2.2 & 2.5 & 2.7 & 4.0 \\
\hline $\mathrm{SyCH}=\mathrm{CHCHO}(E)$ & 6.6 & 7.6 & 6.6 & 6.6 \\
\hline SyH & 4.0 & 4.3 & 4.4 & 10.0 \\
\hline $\mathrm{SyCOCH}_{2} \mathrm{CH}_{3}$ & 2.2 & 2.2 & 1.8 & 1.0 \\
\hline $\mathrm{SyCOCH}_{3}$ & 6.6 & 5.8 & 6.6 & 2.6 \\
\hline SyCHO & 15.8 & 9.8 & 9.7 & 6.1 \\
\hline $\mathrm{GuCH}_{2} \mathrm{CH}_{3}$ & 2.9 & 2.9 & 3.5 & 1.2 \\
\hline $\mathrm{GuCH}_{3}$ & 5.1 & 5.4 & 6.6 & 2.6 \\
\hline $\mathrm{GuCH}_{2} \mathrm{COCH}_{3}$ & 1.8 & 1.8 & 1.8 & 1.4 \\
\hline $\mathrm{GuCH}=\mathrm{CHCHO}(E)$ & 2.2 & 2.5 & 2.7 & 2.9 \\
\hline $\mathrm{GuH}$ & 5.9 & 5.4 & 6.2 & 2.8 \\
\hline $\mathrm{GuCHO}$ & 1.5 & 1.4 & 1.3 & 2.2 \\
\hline
\end{tabular}


smouldering combustion only. The proportions of $\mathrm{SyCH}=\mathrm{CH}_{2}$ and $\mathrm{SyH}$ are higher for smoke from choked burning, which may be explained by decarboxylation of $\mathrm{SyCH}=\mathrm{CHCOOH}$ and SyCOOH (Tóth \& Potthast, 1984). Only the most volatile 2-methoxyphenols $\mathrm{GuH}, \mathrm{GuCH}_{3}$ and $\mathrm{GuCH}_{2} \mathrm{CH}_{3}$ are expected to be gaseous at the low temperature in the curing chamber (Hawthorne et al., 1989). The elevated proportions of these species compared with smoke from choked burning are consistent with a more rapid uptake by the sausages of the particulate methoxyphenols.

The sample from choked burning permits comparisons with the methoxyphenol composition of smoke from other biomass materials generated by the same method (Kjälstrand et al., 2000). Birchwood gives an even lower and grass and heather a much higher ratio between 2-methoxyphenols and 2,6-dimethoxyphenols. Different softwood materials give rise to 2methoxyphenols only, with $\mathrm{GuCH}=\mathrm{CHCH}_{3}, \mathrm{GuCH}=\mathrm{CH}_{2}$ and $\mathrm{GuCHO}$ as major components.

Reported methoxyphenol proportions of many liquid smoke preparations differ widely from the proportions in Table 2, although the liquids are produced from hardwood smoke (Guillén \& Ibargoitia, 1998, 1999; Tóth \& Potthast, 1984). Major assessed components are often $\mathrm{GuH}, \mathrm{GuCH}_{3}, \mathrm{SyH}$ and $\mathrm{SyCH}_{3}$. This is probably explained by higher smoke generation temperatures and losses during the subsequent processing steps, rather than by differences in smoke composition between different hardwood species.

\subsection{Antioxidant aspects}

The methoxyphenols in Table 2 have been ranked according to estimated antioxidant activity (Kjällstrand \& Petersson, 2001b). The additional methoxyl group in the 2,6dimethoxyphenols makes them stronger antioxidants than the corresponding 2-methoxyphenols. 
The antioxidant strength and the redox potential are governed by the stability of the phenoxy radical (Simic, 1992; Lind, Shen, Eriksen \& Merényi, 1990). Conjugation between a side-chain double bond and the aromatic ring therefore increases the antioxidant activity. An electronwithdrawing $\alpha$-carbonyl group decreases the antioxidant strength. The ranking is based mainly on recent studies of antioxidant activity of selected methoxyphenols and related compounds (Barclay et al., 1997; Ogata et al., 1997).

The prevention of lipid peroxidation by breaking radical reaction chains is considered to be the most important antioxidant effect of curing smoke. This effect is linked to the phenolic fraction of the smoke (Tóth \& Potthast, 1984). A lipophilic character of the phenols should favour their penetration into lipids and consequently their antioxidative effect. The methoxyphenols with an alkenyl or an alkyl side-chain appear to possess both a higher antioxidant activity and a higher lipophilicity compared to the carbonyl-containing methoxyphenols.

The high content of about $15 \%$ of the trans isomer of $\mathrm{SyCH}=\mathrm{CHCH}_{3}$ and the total high proportion of $20-25 \%$ of the first three 1-alkenyl phenols in Table 2 are likely to contribute strongly to the antioxidant properties of the smoke. The proportion of these methoxyphenols is reported to be much lower in liquid and solid smoke (Tóth \& Potthast, 1984; Guillén \& Manzanos, 1997; Guillén \& Ibargoitia, 1998). The proportions of GuH and SyH with low antioxidant activity are much lower in the alder smoke than in the liquid and solid smoke preparations. It is also interesting that vanillin, GuCHO, as the most well-known methoxyphenol, appears to be the weakest antioxidant.

The methoxyphenols in smoked meat products may also be important with respect to intake of antioxidants with food. Interest in dietary phenolic antioxidants for improved health and 
prevention of diseases has increased sharply in recent years (Newmark, 1996). In the living cell, methoxyphenols may be important not only as chain breakers in lipid peroxidation, but also as scavengers of peroxidation-initiating aqueous superoxide ions (Ogata et al., 1997). A potential effect of the methoxyphenols depends on the uptake and distribution of the compounds in the body. For workers at the smoking plant, respiratory uptake of the methoxyphenol antioxidants should be considered as well as exposure to toxic smoke components.

\subsection{Smoke curing procedure}

Curing in a smoke chamber with freshly generated alder smoke, according to the investigated procedure, offers several advantages. The hardwood produces smoke with a high proportion of 2,6-dimethoxyphenols, which have stronger protective antioxidant activity than 2methoxyphenols from softwood. The smouldering bed of alder wood particles in the smoke generator permits keeping a constantly low combustion temperature. This results in a high proportion of the particularly antioxidative methoxyphenols with an alkenyl side-chain. It also keeps the concentrations of hazardous polycyclic aromatic compounds at a very low level. A drawback is the high concentration of benzene in the curing atmosphere, but benzene appears to be much less absorbed than the major methoxyphenols, which are condensed on smoke particles.

\section{References}

Alén, R., Kuoppala, E., \& Oesch, P. (1996). Formation of the main degradation compound groups from wood and its components during pyrolysis. Journal of Analytical and Applied Pyrolysis, 36, 137-148. 
Barclay, L. R. C., Xi, F., \& Norris, J. Q. (1997). Antioxidant properties of phenolic lignin model compounds. Journal of Wood Chemistry and Technology, 17(1-2), 73-90.

Barrefors, G., Björkqvist, S., Ramnäs, O., \& Petersson, G. (1996). Gas chromatographic separation of volatile furans from birchwood smoke. Journal of Chromatography A, 753, 151155.

Barrefors, G., \& Petersson, G. (1995). Volatile hydrocarbons from domestic wood burning. Chemosphere 30(8), 1551-1556.

García Falcón, M. S., González Amigo, S., Lage Yusty, M. A., López de Alda Villaizán, M. J., \& Simal Lozano, J. (1996). Enrichment of benzo[a]pyrene in smoked food products and determination by high-performance liquid chromatography-florescence detection. Journal of Chromatography A, 753, 207-215.

Guillén, M. D., \& Ibargoitia, M. L. (1998). New components with potential antioxidant and organoleptic properties, detected for the first time in liquid smoke flavoring preparations. Journal of Agricultural and Food Chemistry, 46, 1276-1285.

Guillén, M. D., \& Ibargoitia, M. L. (1999). Influence of the moisture content on the composition of the liquid smoke produced in the pyrolysis process of Fagus sylvatica L. wood. Journal of Agricultural and Food Chemistry, 47, 4126-4136.

Guillén, M. D., \& Manzanos, M. J. (1997). Characterization of the components of a salty smoke flavouring preparation. Food Chemistry, 58(1-2), 97-102.

Hawthorne, S. B., Krieger, M. S., Miller, D. J., \& Mathiason, M. B. (1989). Collection and quantitation of methoxylated phenol tracers for atmospheric pollution from residential wood stoves. Environmental Science and Technology, 23(4), 470-475.

Kjällstrand, J., Ramnäs, O., \& Petersson, G. (2000). Methoxyphenols from burning of Scandinavian forest plant materials. Chemosphere, 41, 735-741. 
Kjällstrand, J., \& Petersson, G. (2001a). Phenols and aromatic hydrocarbons in chimney emissions from traditional and modern residential wood burning. Environmental Technology, in press.

Kjällstrand, J., \& Petersson, G. (2001b). Phenolic antioxidants in wood smoke. The Science of the Total Environment, in press.

Lind, J., Shen, X., Eriksen, T. E., \& Merényi, G. (1990). The one-electron potential of 4substituted phenoxyl radicals in water. Journal of the American Chemical Society, 112, 479-482. Newmark, H. L. (1996). Plant phenolics as potential cancer prevention agents. In Dietary phytochemicals in cancer prevention and treatment (pp. 25-34), New York: Plenum Press.

Ogata, M., Hoshi, M., Shimotohno, K., Urano, S., \& Endo, T. (1997). Antioxidant activity of magnolol, honokiol, and related phenolic compounds. Journal of the American Oil Chemists' Society, 74(5) 557-562.

Putnam, K. P., Bombick, D. W., Avalos, J. T., \& Doolittle, D. J. (1999). Comparison of the cytotoxic and mutagenic potential of liquid smoke food flavourings, cigarette smoke condensate and wood smoke condensate. Food and Chemical Toxicology, 37, 1113-1118.

Simic, M. G. (1992). Antioxidant compounds: an overview In: K. J. A. Davies, Oxidative damage and repair (pp. 47-59), New York: Pergamon Press.

Simoneit, B. R. T., Schauer, J. J., Nolte, C. G., Oros, D. R., Elias, V. O., Fraser, M. P., Rogge, W. F., \& Cass, G. R. (1999). Levoglucosan, a tracer for cellulose in biomass burning and atmospheric particles. Atmospheric Environment, 33, 173-182.

Tóth, L., \& Potthast, K. (1984). Chemical aspects of the smoking of meat and meat products. Advances in Food Research, 29, 87-158. 